\title{
Production of Fibronectin by Epithelium in a Skin Equivalent
}

\author{
Edward J. O'Keefe, M.D., David T. Woodley, M.D., Ronald J. Falk, M.D., W. Ray Gammon, M.D., \\ and Robert A. Briggaman, M.D. \\ Department of Dermatology, University of North Carolina, Chapel Hill, North Carolina, U.S.A.
}

\begin{abstract}
Although human keratinocytes in vitro have been shown to produce fibronectin, whether keratinocytes can contribute fibronectin to the dermal-epidermal junction or wound matrix is unknown. In order to approach this problem experimentally, we used the "skin equivalent" model composed of a native collagen gel populated with cultured fibroblasts and covered by cultured keratinocytes. By using bovine fibroblasts to populate the gel, fetal bovine serum in the culture medium, and human keratinocytes to form the epithelium, we were able to be certain that any human fibronectin produced in the culture was synthesized by the keratinocytes. A monoclonal antibody to fibronectin was found to recognize human but not bovine fibronectin. When the skin equivalent was stained by indirect immunofluo-
\end{abstract}

rescence with antifibronectin, fibronectin was visible as an intensely staining band at the dermal-epidermal junction. In sections in which the dermis and epidermis had separated, the staining was usually limited to the dermal aspect of the skin equivalent. The results indicate that epithelium can contribute fibronectin to the dermal-epidermal junction and suggest that dermal staining in skin sections may originate from the epidermis. Since the developing skin equivalent has a rapidly growing epithelium and simulates a healing wound, contribution of fibronectin by the epithelium, in addition to that possibly contributed by serum and dermal fibroblasts, may be of importance in wound healing. J Invest Dermatol 88:634-639, 1987

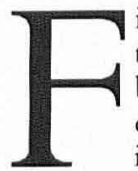

ibronectin is a $440 \mathrm{kD}$ asymmetric dimeric glycoprotein that has binding sites for molecules of the dermal matrix, basement membrane, and cells [1]. Although keratinocytes in culture have been shown to produce soluble and insoluble fibronectin [2-7], the physiologic function of fibronectin secreted by the epithelial cells is uncertain, since normal epidermis does not contain fibronectin. In order to determine whether fibronectin can be produced in a situation more closely resembling that of the epidermis in vivo, we used the model of the skin equivalent devised by Bell et al [8]. Fibroblasts were plated in a collagen gel, which then contracted to a dense collagenous disc. The disc was plated with keratinocytes, which were allowed to form an epithelium on the surface of the disc. Although the structure is clearly not truly an "equivalent" of skin, the results show that the epithelium can contribute fibronectin in this model and that the contributed fibronectin is deposited at the junction of the epithelium with the collagenous lattice.

\section{MATERIALS AND METHODS}

Cell Culture Bovine tracheal fibroblasts (ATCC CCL 44) were obtained from the American Type Culture Collection (Rockville,

\footnotetext{
Manuscript received August 19, 1986; accepted for publication November $19,1986$.

This study was supported by National Institutes of Health grants AM25871, AM00977, AM01540, AM33625, AM30475, AM10546, and AM34855

Reprint requests to: Edward J. O'Keefe, M.D., Department of Dermatology, 137 NCMH, Chapel Hill, North Carolina 27514.

Abbreviations:

DMEM: Dulbecco's modification of Eagle's medium

FBS: fetal bovine serum

PBS: phosphate-buffered saline
}

Maryland) and cultured in Dulbecco's minimum essential medium (DMEM) with 10\% fetal bovine serum (FBS). Human epidermal keratinocytes were obtained from neonatal foreskins and initiated into culture according to Rheinwald and Green [9] and then subcultured in MCDB 153 medium supplemented with epidermal growth factor, $5 \mathrm{ng} / \mathrm{ml}$; insulin, $5 \mu \mathrm{g} / \mathrm{ml}$; hydrocortisone, $0.4 \mu \mathrm{g} / \mathrm{ml}$; ethanolamine, $0.1 \mathrm{~mm}$; phosphoethanolamine, $0.1 \mathrm{~mm} ; \mathrm{CaCl}_{2}, 0.1 \mathrm{~mm}$; and bovine pituitary extract [10].

Production of the Skin Equivalent Rat tail tendons from 8 rat tails were extracted for $72 \mathrm{~h}$ at $4^{\circ} \mathrm{C}$ in $250 \mathrm{ml}$ of $17 \mathrm{~mm}$ acetic acid and centrifuged at $48,000 \mathrm{~g}$ for $30 \mathrm{~min}$. The supernatant was stored in a sterile container at $4^{\circ} \mathrm{C}$. To make one collagen gel, we quickly mixed $2.0 \mathrm{ml}$ of the collagen solution and $1.26 \mathrm{ml}$ of solution containing $0.8 \mathrm{ml} 3 \times$ concentrated DMEM, $0.4 \mathrm{ml}$ FBS, and $0.06 \mathrm{ml} 0.4 \mathrm{~N} \mathrm{NaOH}$ with $0.8 \mathrm{ml}$ of complete medium containing $1 \times 10^{5}$ fibroblasts in a $60-\mathrm{mm}$ Petri dish. The dishes containing the gels received new medium every 3 days and were allowed to contract for 3-5 days. When the gels had contracted sufficiently they were transferred to $2-\mathrm{cm}^{2}$ wells of a 24-well tray and plated with $2 \times 10^{4}$ cultured keratinocytes per well from a subconfluent culture in medium composed of $50 \%$ DMEM, $50 \%$ Ham's F-12 with 5\% FBS, insulin $(5 \mu \mathrm{g} / \mathrm{ml})$, epidermal growth factor $(10 \mathrm{ng} / \mathrm{ml})$, and hydrocortisone $(0.4 \mu \mathrm{g} / \mathrm{ml})$ and containing $1.1 \mathrm{mM} \mathrm{Ca}^{++}$. The keratinocytes were cultured for 3 weeks on the submerged collagen disk, during which time they formed an epithelium over the surface of the contracted collagen lattice.

Immunoblotting Forty micrograms of human fibronectin (BRL Laboratories, Bethesda, Maryland) or bovine fibronectin (prepared according to Hayashi and Yamada, [11]) were subjected to sodium dodecyl sulfate-polyacrylamide gel electrophoresis and Western blotting as described by Towbin et al [12] and modified as previously described [13]. Nitrocellulose strips with immo- 
bilized human or bovine fibronectin were incubated with the monoclonal antifibronectin antibody diluted $1: 100\left(4 \mathrm{~h}, 24^{\circ} \mathrm{C}\right)$, washed 5 times in $0.01 \mathrm{M}$ Tris-HCL, $0.25 \mathrm{M} \mathrm{NaCl}, 0.3 \%$ Nonidet $\mathrm{P}-40, \mathrm{pH} \mathrm{7.4}$, and then incubated with peroxidase-conjugated antimouse $\operatorname{IgG}$ diluted $1: 400\left(2 \mathrm{~h}, 24^{\circ} \mathrm{C}\right)$. The strips were washed again and developed with 4-chloro-1-napthol (Bio-Rad, Rockville Centre, New York), dried, and photographed.

Immunofluorescence Cultured cells on glass coverslips were fixed for $15 \mathrm{~min}$ in $3.7 \%$ buffered formaldehyde, washed with Dulbecco's phosphate-buffered saline (PBS), extracted for $5 \mathrm{~min}$ with $0.5 \%$ Triton X-100 in PBS, and washed in PBS. The coverslips were incubated with $1: 100$ dilution of ascites fluid containing monoclonal antifibronectin or normal mouse serum diluted 1:100 as control for $30 \mathrm{~min}$ in a humidified chamber, rinsed with PBS, and incubated with fluorescein-conjugated goat antimouse $\operatorname{IgG}$ $(1: 20)$ for $30 \mathrm{~min}$. They were then washed, mounted in Gelvatol (Monsanto, St. Louis, Missouri), and examined under cpifluorescence optics.

The skin equivalents were frozen in liquid nitrogen, sectioned in a cryostat at $4 \mu \mathrm{m}$, and incubated and examined similarly. In some cases sections were also incubated with rabbit antikeratin antibody $(1: 50)$ and rhodamine-conjugated sheep antirabbit $\operatorname{IgG}$ $(1: 20)$ and then mounted. Cells or tissues were photographed in a Leitz epifluorescence microscope with Kodak Tri-X film at an ASA of 1600. Film was developed in Diafine (Acufine, Inc., Chicago, Illinois).

Electron Microscopy For routine examination the skin equivalents were fixed in half-strength Karnovsky's fixative, postfixed in osmium tetroxide, embedded in Polybed 812 (Polysciences, Warrington, Pennsylvania), stained with uranyl acetate and lead acetate, and processed and examined in a JEM 100B electron microscope.

Frozen skin equivalents were cut in $10-\mu \mathrm{m}$ sections and air dried. The tissue was incubated with antifibronectin ascites fluid $(1: 100)$ or normal mouse serum diluted $1: 100$ as control, washed, and then incubated with goat antimouse $\operatorname{IgG}(1: 20)$, rabbit antigoat IgG (1:1 in 50\% normal rabbit serum), goat anti-horseradish peroxidase (1:1 in 50\% normal rabbit serum), and horseradish peroxidase $(5 \mu \mathrm{g} / \mathrm{ml})$. The tissue was incubated in the reagents for $30 \mathrm{~min}$ and washed twice with PBS between incubations. Sections were then fixed and stained as described [14].

Materials The monoclonal antifibronectin antibody, designated MBM20, has been previously characterized [15]. Fluorophoreconjugated second antibodies were from Cappel (Malvern, Pennsylvania), and rabbit antikeratin antibody was from Accurate Chemical and Scientific Corp. (Westbury, New York). DMEM was from GIBCO (Grand Island, New York) and FBS was from Hyclone (Logan, Utah). Chemicals used for MCDB 153 medium were from Sigma Chemical Co. (St. Louis, Missouri). Other chemicals were from Fisher Scientific (Springfield, New Jersey), and plastic tissue culture ware was from Corning, (Corning, New York).

\section{RESULTS}

Specificity of Antifibronectin In order to demonstrate that the monoclonal antifibronectin antibody detected only human and not bovine fibronectin, 2 control experiments were performed. First, purified bovine and purified human fibronectin were tested on immunoblots using the antibody to detect the immobilized fibronectin. As shown in Fig 1, amido black staining of lanes containing human and bovine fibronectin demonstrated clearly that both proteins were transferred to nitrocellulose paper. The immunoblot, however, showed only human fibronectin; bovine fibronectin was not detected.

Second, in order to further demonstrate that the antibody was specific for human fibronectin in immunofluorescence, we examined cultures of bovine and human fibroblasts. As shown in Fig 2, formaldehyde-fixed human cells showed characteristic ex-

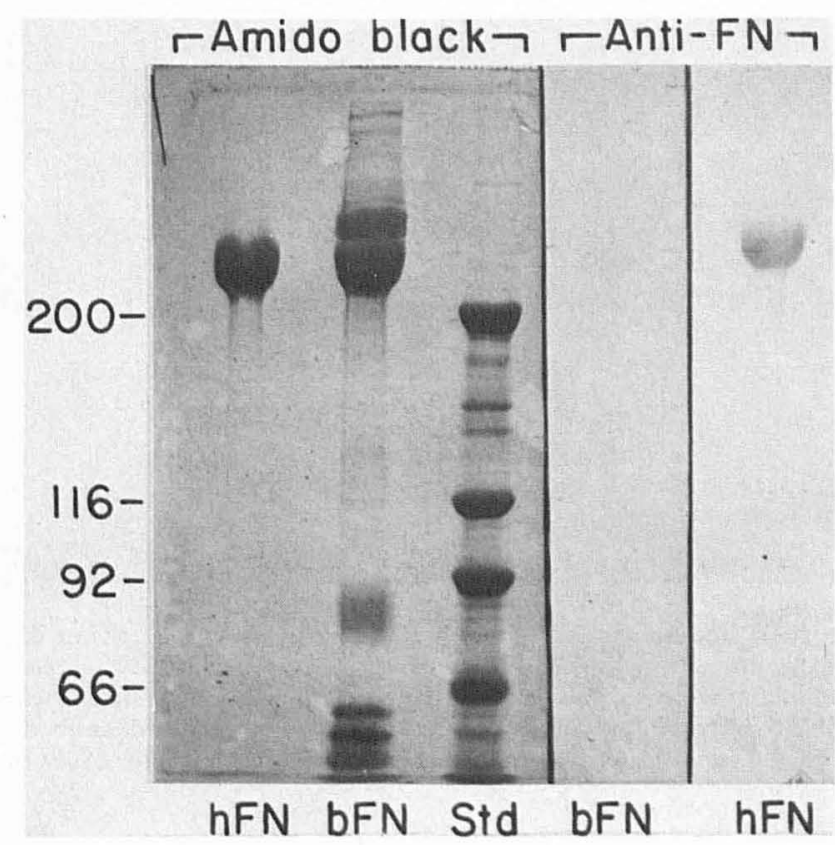

Figure 1. Immunoblot of human and bovine fibronectin using monoclonal antifibronectin. Procedures were performed as in Materials and Methods. The 3 lanes on the left were stained with amido black to demonstrate transfer of proteins to nitrocellulose paper, and the 2 lanes on the right were developed using antifibronectin antibody and peroxidaseconjugated antimouse IgG. Numbers indicate molecular weights in kilodaltons of standards shown in the middle lane. hFN, human fibronectin; $b F N$, bovine fibronectin; Std, molecular weight standards.

tracellular fibrils of fibronectin, but bovine cells did not. Control experiments using a polyclonal rabbit antibody to human fibronectin [6] which stained both human and bovine fibronectin showed that the bovine cells stained for fibrillar extracellular fibronectin (not shown). We concluded that the monoclonal antibody detected human but not bovine fibronectin both in immunofluorescence and in immunoblots.

Examination of the Skin Equivalent for Fibronectin In order to determine whether human keratinocytes in an epithelium could deposit fibronectin, we constructed a skin equivalent in which only the keratinocytes were of human origin; the fibroblasts in the collagen lattice were bovine. To determine whether
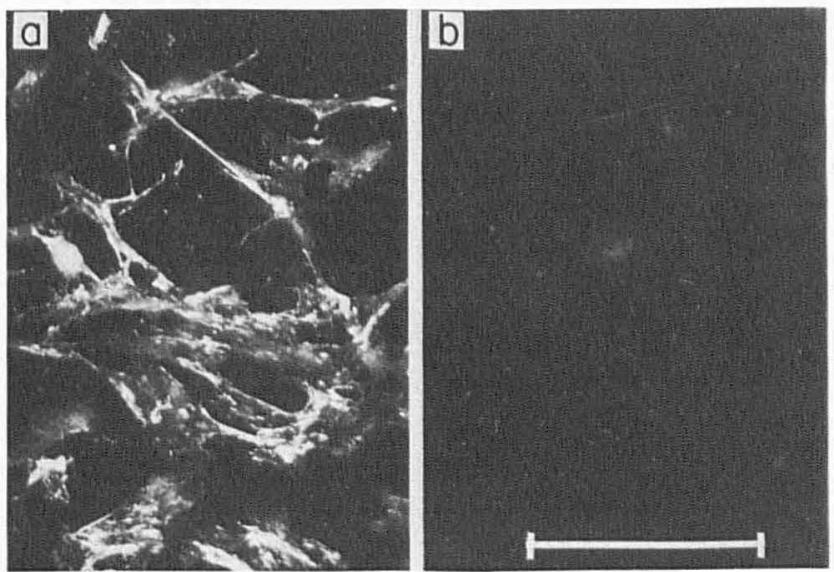

Figure 2. Immunofluorescence of fibronectin in human or bovine fibroblasts using monoclonal antifibronectin antibody. a, Human dermal fibroblasts. b, Bovine fibroblasts. Cells were prepared as in Materials and Methods. Scale bar $=200 \mu \mathrm{m}$. 


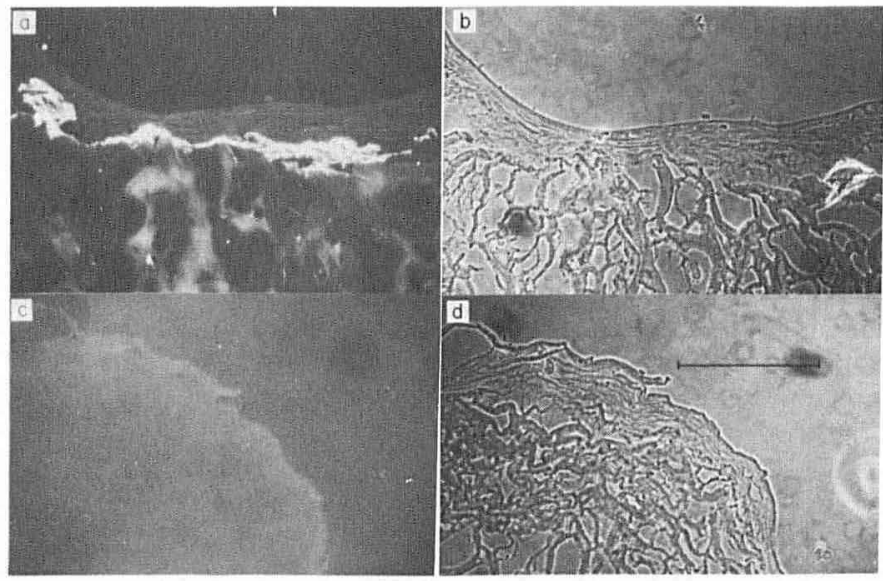

Figure 3. Immunofluorescence and phase contrast micrographs of skin equivalent stained with antifibronectin and control antibody. $a$ and $c$, Immunofluorescence. $b$ and $d$, Phase contrast. $a$ and $b$, Section stained with antifibronectin antibody. $c$ and $d$, Section stained with control antibody. Sections were prepared and stained as in Materials and Methods. Scale bar $=200 \mu \mathrm{m}$

human fibronectin was present in the skin equivalent composed of bovine fibroblasts, rat-tail collagen, and human keratinocytes, we stained frozen sections of the skin equivalent using the monoclonal antifibronectin. As is shown in Fig $3 a$, fibronectin was demonstrated at the junction of the collagen lattice and the epithelium, which can be located by comparison with the phasecontrast image (Fig 3b).

In areas where the epithelium had separated from the underlying collagen lattice, 2 observations indicated that the fibronectin often remained with the collagen (Fig 4a). First, careful examination of the skin equivalent by phase contrast microscopy showed a clear separation between epithelium and collagen lattice (Fig $4 b)$. Second, frozen sections stained with rhodamine (Fig 5a) and fluorescein (Fig 5b) for both keratin and fibronectin showed that areas of collagen with deposited fibronectin did not contain keratin.

Figure 6 shows the plasma membrane of the basal aspect of a keratinocyte apposed to the collagen lattice in a 3-week-old skin equivalent. No basement membrane structures including lamina densa, lamina lucida, hemidesmosomes, and anchoring fibrils were
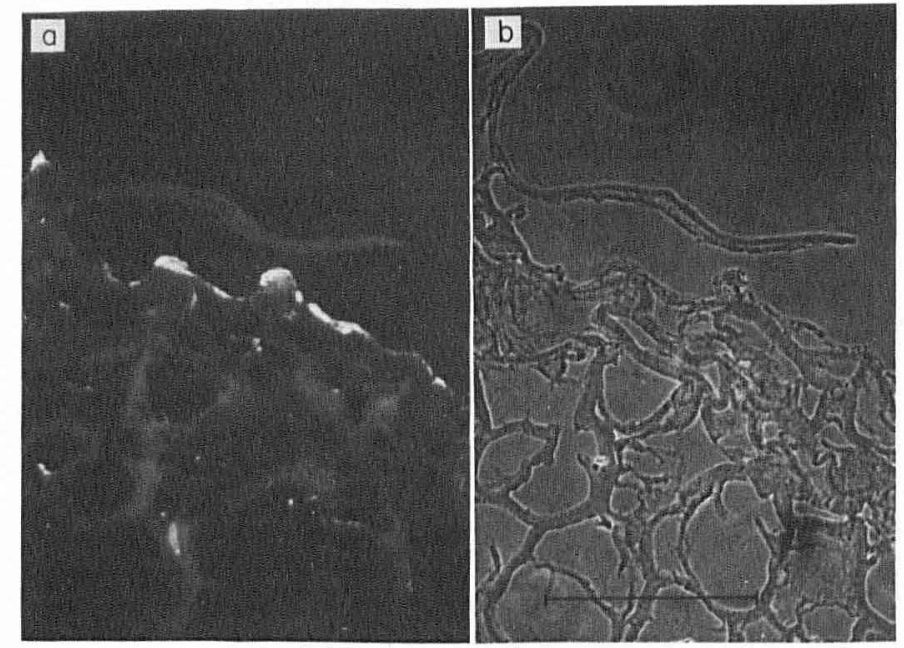

Figure 4. Immunofluorescence and phase contrast micrographs of section of skin equivalent showing separation of the epithelium from the collagen lattice. $a$, Immunofluorescence. $b$, Phase contrast. Sections were prepared and stained as in Materials and Methods. Scale bar $=200 \mu \mathrm{m}$.
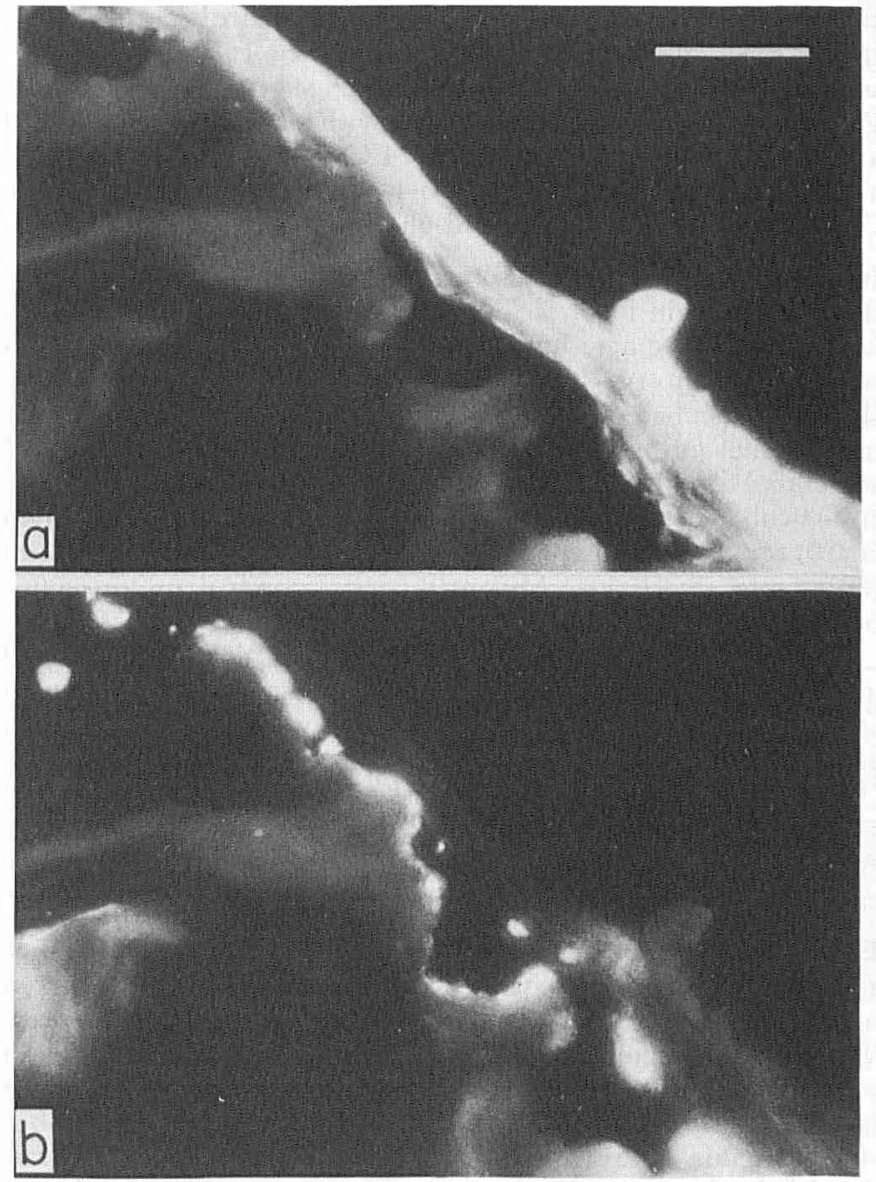

Figure 5. Double immunofluorescence of keratin and fibronectin in a skin equivalent in which the epithelium has separated from the collagen lattice. $a$, Staining of keratin with rabbit antikeratin and rhodamine-conjugated sheep antirabbit IgG. $b$, Staining of fibronectin with monoclonal antifibronectin and fuorescein-conjugated goat antimouse IgG. Scale bar $=100 \mu \mathrm{m}$

formed in our skin equivalents even 3 weeks after the collagen lattice had been plated with keratinocytes. Frozen sections showed a well-stratified epithelium in this and 12 other skin equivalents studied (not shown), suggesting that the epithelium had been present long enough to begin to lay down basement membrane structures. Although the skin equivalent contained type IV collagen and very small amounts of laminin and pemphigoid antigen in discontinuous linear deposits at the base of the epithelium by immunofluorescence (data not shown), these components were not organized into structures of the basal lamina and lamina lucida. The skin equivalent grown in this fashion did not show keratohyaline granules, further indicating that it was not the equivalent of mature skin.

Immunoelectron microscopy (Fig 7) confirmed that the fibronectin deposited in the skin equivalent was located in the region of the junction of dermis and epidermis. The immune deposits were found between the epithelium, which contained intermediate filaments, and the dermis-like structure containing collagen fibers. The experimental section, Fig $7 a$, incubated with antifibronectin antiserum, shows deposits of fibronectin at the interface (arrows) between the keratinocyte and the collagen lattice; the control section incubated with normal mouse serum, Fig $7 b$, shows no deposits. The plasma membrane of the basal cell adjacent to the collagen lattice was not visible in tissues processed for immunoelectron microscopy because of the loss of detail that occurred during processing. These electron microscopic findings indicate that fibronectin was produced and deposited beneath the 
Figure 6. Electron micrograph of skin equivalent showing junction of epithelium and collagen lattice. E, Epithelial keratinocyte (nucleus); $C$, collagen lattice; arrow, plasma membrane of keratinocyte. Section was processed as in Materials and Methods. Scale bar $=1 \mu \mathrm{m}$.

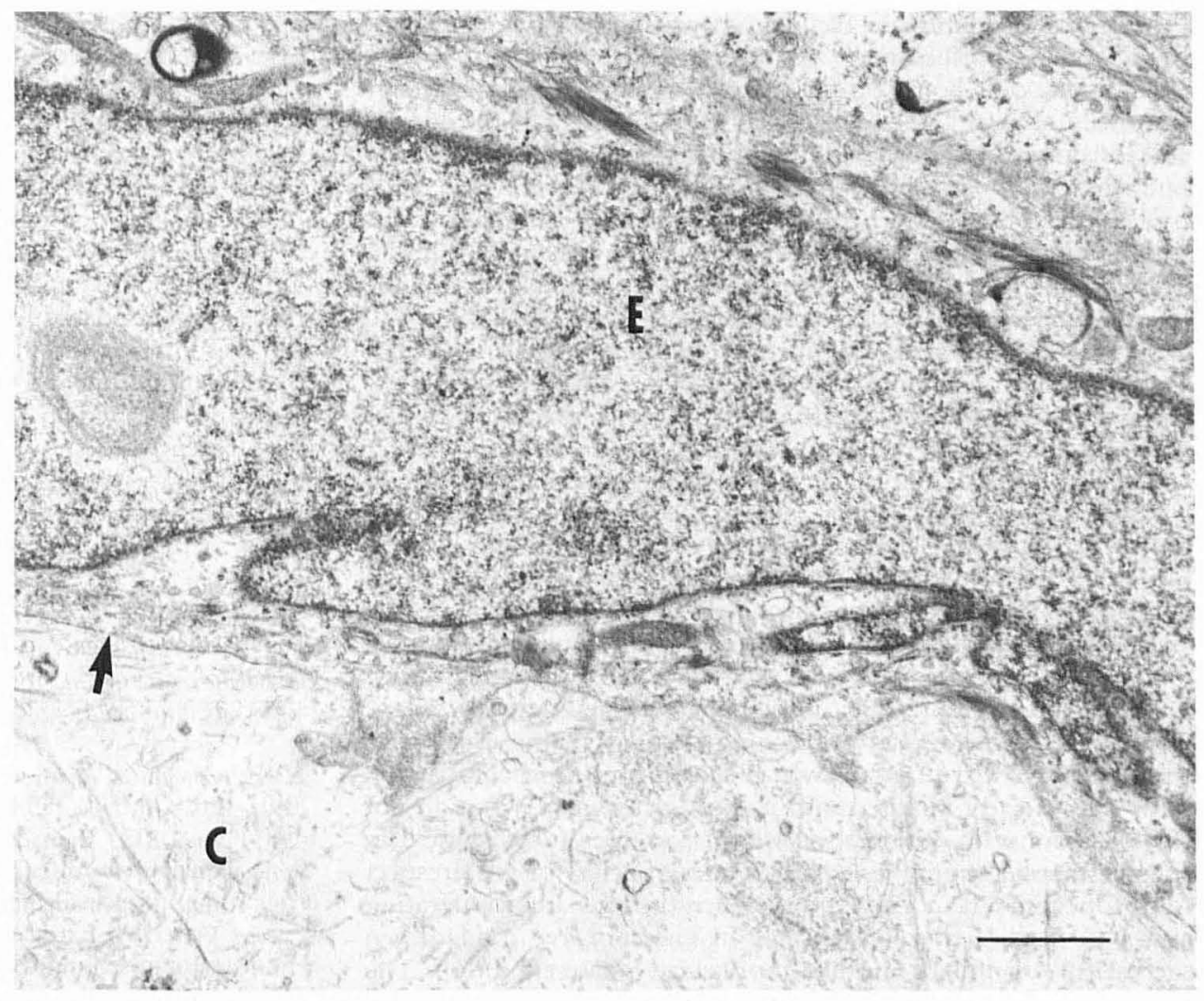

epithelium at a time when no basement membrane structures were present.

Fibronectin was deposited in a similar location, at the junction of the epithelium and the collagen lattice, both in areas where the epithelium was just beginning to cover the collagen lattice and was therefore only 1 or 2 cell layers thick (not shown), and in areas where there was a multilayered stratified epithelium. We were not able to distinguish whether more or less fibronectin was present under these different conditions, and fibronectin did not diminish or disappear as the epithelium thickened. Fibronectin

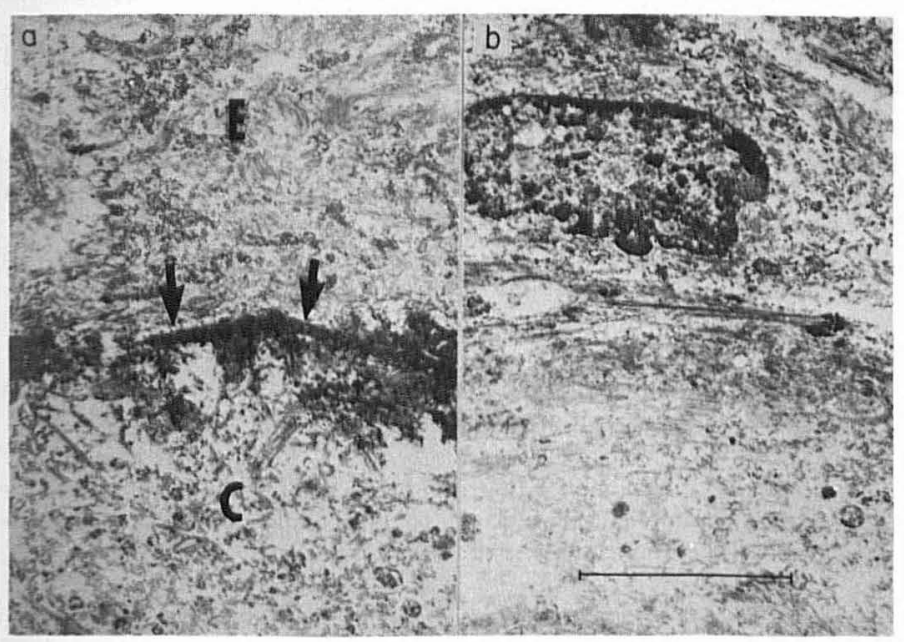

Figure 7. Immunoelectron micrograph of skin equivalent stained with antifibronectin antibody. Section was processed as in Materials and Methods. Dark deposits in (a) (arrows) indicate location of fibronectin at junction of keratinocyte and collagen lattice. $a$, Section incubated with antifibronectin antibody. $b$, Section incubated with control serum. $E$, epithelial keratinocyte; $C$, collagen lattice. Scale bar $=2 \mu \mathrm{m}$. was present at the leading edge of the epithelial tongue and discontinuously throughout the region of the interface in all sections.

\section{DISCUSSION}

The biologic role of fibronectin in the epithelium or at the boundary of epithelium and mesenchymal tissues has been addressed in many papers [16-20]. Although initial light microscopic studies suggested that fibronectin was present in basement membranes $[21,22]$, later work using electron microscopy indicated that fibronectin was present primarily in the connective tissue and was absent from the basement membrane in most tissues [17]. Nevertheless, several studies suggested that fibronectin may have a direct effect on epithelium [23-25]. The role of fibronectin in guiding development of epithelium in embryogenesis was suggested, for example, by findings in the eye and the neural crest (reviewed in [26]).

Our study suggests that fibronectin secreted by the nascent epithelium may have a role parallel to that of fibronectin in mesenchymal tissues, acting primarily as a cement. Fibronectin may facilitate adhesion of the epithelial layer to the dermis before assembly of basement membrane proteins, including laminin, type IV collagen, heparan sulfate proteoglycan, and pemphigoid antigen, which are found on the epithelial aspect of fibronectin deposits in mature normal skin, into basement membrane structures which form a more permanent cement. Studies of cultured epithelial cells are consistent with the role of fibronectin as an adhesion protein in keratinocytes. Fibronectin was recognized to form a 3-dimensional array around fibroblasts in culture as well as in tissue, but cultured epithelial cells were found to produce fibronectin localized between the cell and the substratum [2-7]. Fibronectin enhanced spreading and attachment of keratinocytes [27-30], improving the strength of the binding of the cells to the surface. The action on epithelium of fibronectin in a wound or in development may be similar. In dermis and subcutancous tissues, fibronectin serves as a framework for deposition of collagen and possibly other mesenchymal matrix molecules during healing 
[31], and it may similarly facilitate formation of basement membrane beneath epithelium.

Epithelial cells both secrete and are dramatically influenced by fibronectin. First, keratinocytes synthesize and secrete fibronectin and lay down fibrillar insoluble fibronectin in culture [2-7]. Second, these cells were shown to deposit fibronectin in tracks made by the cells plated on a bed of colloidal gold, documenting that the deposition of fibronectin correlated with movement [32]. Third, keratinocyte motility was dramatically stimulated by insoluble fibronectin [32]. Finally, keratinocyte attachment, spreading, and growth were enhanced on fibronectin-coated surfaces [27,28]. Therefore, fibronectin, once proposed to interact with fibroblasts but not with epithelial cells [33], in fact has remarkably similar actions in both types of cells.

Keratinocytes in culture may be more analogous to keratinocytes during wound healing than to stable unwounded epithelium. For example, keratinocytes do not recognize and bind fibronectin when introduced into culture but only after 2 days in culture $[34,35]$. This lack of fibronectin receptor function may be associated with failure of keratinocytes from confluent cultures, unlike proliferating subconfluent keratinocytes, to spread, as noted by Stenn and Milstone [36]. Since fibronectin facilitates spreading, newly introduced cells from culture, perhaps analogous to cells freshly obtained from skin, which spread poorly in comparison with cells already initiated into culture, presumably also do not secrete fibronectin during this early period in culture. These data suggest that keratinocytes have 2 modes of behavior with respect to fibronectin: a responsive mode when the cells are proliferating and synthesizing fibronectin; and an unresponsive mode when the cells are confluent and in a more steady-state condition. The in vivo correlates of these modes may be keratinocytes in wounded and stable epithelium.

Although our skin eqivalents produced stratified epithelium, they were less fully differentiated than skin. A basal lamina was absent, and some basement membrane antigens were present only in small amounts. Bohnert et al [37] also failed to find basement membrane structures using mouse epidermal cells plated on collagen gels without fibroblasts despite the presence of fibronectin and basement membrane antigens including laminin, type IV collagen, and pemphigoid antigen. Placement of the gels in chambers permitting contact with dermis in vivo, however, even with separation by the collagen gel of dermis and epidermis, permitted development of basement membrane structures demonstrable by electron microscopy. Bohnert et al concluded that mesenchymal influences were required to organize the secreted proteins into basement membrane structures and also suggested that fibronectin in their model originated from the epidermis. More complete differentiation than occurred in our models was obtained by Asselineau et al [38], who lifted the skin equivalent structures made with human cells to the air/medium interface on grids and demonstrated synthesis of keratohyaline granules, laminin, pemphigoid antigen, and fibronectin, but did not discuss the origin of these proteins. Their tissues were still abnormal in comparison with epidermis in vivo, however, since these and other antigens were abnormally distributed. In contrast, the studies of Briggaman et al [39] indicated that epithelium applied to the chick chorioallantoic membrane could synthesize a mature basal lamina within 7 days, suggesting that the embryo is able to supply components which are lacking in the skin equivalent in vitro.

The presence of fibronectin in epithelium after wounding and in several skin diseases (reviewed by Clark [26]) raised the possibility that fibronectin found in these situations originated from fibroblasts or from serum flooding the wound, a possibility supported experimentally by studies showing that human plasma fibronectin could be deposited in tissues of mice [40], and by the finding that that soluble fibronectin can be cross-linked to fibrin by plasma transglutaminase [41]. In wound healing experiments, fibronectin was found at the base of the tongue of healing epithelium, and the epidermis was found to migrate on a base containing fibronectin, among other proteins. Later, when migration had ceased, fibronectin disappeared. This suggested that fibronectin flooding a wound was removed when healing was complete (reviewed by Clark [26]). A similar scenario has been proposed for fibronectin in healing subcutaneous tissue $[42,43]$ and more recently by Fujikawa et al [19] and Takashima et al [35] in epithelial healing. Although we did not find evidence for removal of fibronectin, our model is arrested in development at a point before assembly of basement membrane components.

Even though the skin equivalent is abnormally and incompletely differentiated $[37,38]$, our study indicates that fibronectin can be contributed to the region of the dermal-epidermal junction by the epithelium and suggests that the secreted fibronectin may also be deposited in the dermis. Species-specific antibody was used recently to show that basal cell carcinoma cells implanted in nude mice can secrete fibronectin in the extracellular matrix [44]. This method may be generally applicable in the study of other secreted molecules in addition to fibronectin.

The technical assistance of R. E. Payne, Jr. and M. L. Reese is gratefully acknowledged.

\section{REFERENCES}

1. Hynes RO, Yamada KM: Fibronectins: multifunctional modular glycoproteins. J Cell Biol 95:369-377, 1982

2. Alitalo K, Kuismanen E, Myllya R, Kiistalo U, Aski-Seljavaara S, Vaheri A: Extracellular matrix proteins of human epidermal keratinocytes and feeder 3T3 cells. J Cell Biol 94:497-505, 1982

3. Kariniemi A-L, Lehto V-P, Vartio T, Virtanen I: Cytoskeleton and pericellular matrix organization of pure adult human keratinocytes cultured from suction-blister roof epidermis. J Cell Sci 58:49-61, 1982

4. Brown KW, Parkinson EK: Glycoproteins and glycosaminoglycans of cultured normal human keratinocytes. J Cell Sci 61:325-338, 1983

5. Gibson WT, Couchman JR, Badley A, Saunders HJ, Smith CG: Fibronectin in cultured rat keratinocytes: distribution, synthesis, and relationship to cytoskeletal proteins. Eur J Cell Biol 30:205-213, 1983

6. O'Keefe EJ, Woodley D, Castillo G, Russell N, Payne RE Jr: Production of soluble and cell-associated fibronectin by cultured keratinocytes. J Invest Dermatol 82:150-155, 1984

7. Kubo M, Norris DA, Howell SE, Ryan SR, Clark RA: Human keratinocytes synthesize, secrete, and deposit fibronectin in the pericellular matrix. J Invest Dermatol 82:580-586, 1984

8. Bell E, Ehrlich HP, Buttle DJ, Nakatsuji T: Living tissue formed in vitro and accepted as skin-equivalent of full thickness. Science 211:1052-1054, 1981

9. Rheinwald JG, Green H: Serial cultivation of strains of human epidermal keratinocytes: the formation of keratinizing colonies from single cells. Cell 6:331-344, 1975

10. Boyce ST, Ham RG: Calcium-regulated differentiation of normal human epidermal keratinocytes in chemically defined clonal culture and serum-free serial culture. J Invest Dermatol 81 (suppl): $33 \mathrm{~s}-40 \mathrm{~s}, 1983$

11. Hayashi M, Yamada KM: Divalent cation modulation of fibronectin binding to heparin and to DNA. J Biol Chem 257:5263-5267, 1982

12. Towbin HT, Stachelin T, Gordon J: Electrophoretic transfer of proteins from polyacrylamide gels to nitrocellulose sheets: procedures and some applications. Proc Natl Acad Sci USA 76:4350-4354, 1979

13. Woodley DT, Briggaman RA, O'Keefe EJ, Inman AO, Queen LL, Gammon WR: Identification of the skin basement-membrane autoantigen in epidermolysis bullosa. N Engl J Med 310:1007-1013, 1984

14. Paller AS, Queen LL, Woodley DT, Gammon WR, O'Keefe EJ, Briggaman RA: A mouse monoclonal antibody against a newly discovered basement membrane component, the epidermolysis bullosa acquisita antigen. J Invest Dermatol 84:215-217, 1985 
15. Michael AF, Yang J-Y, Falk RJ, Bennington MJ, Scheinman JI, Vernier RL, Fish AJ: Monoclonal antibodies to human renal basement membranes: heterogenic and ontogenic changes. Kidney Int $24: 74-86,1983$

16. Brownell AG, Bessem CC, Slavkin HC: Possible functions of mesenchyme cell-derived fibronectin during formation of basal lamina. Proc Natl Acad Sci USA 78:3711-3715, 1981

17. Boselli JM, Macarak EJ, Clark EC, Brownell AG, Martinez-Hernandez A: Fibronectin: its relationship to basement membranes. I. Light microscopic studies. Coll Relat Res 5:391-404, 1981

18. Clark RA, Lanigan JM, DellaPelle P, Manscau E, Dvorak HJ, Colvin RB: Fibronectin and fibrin provide a provisional matrix for epidermal cell migration during wound reepithelialization. J Invest Dermatol 79:264-269, 1982

19. Fujikawa LS, Foster CS, Gipson IK, Colvin RB: Basement membrane components in healing rabbit corneal epithelial wounds: immunofluorescence and ultrastructural studies. J Cell Biol 98: 128-138, 1984

20. Repesh LA, Fitzgerald TJ, Furcht LT: Fibronectin involvement in granulation tissue and wound healing in rabbits. J Histochem $\mathrm{Cy}$ tochem 30:351-358, 1982

21. Linder E, Vaheri A, Ruoslahti E, Wartiovaara J: Distribution of fibroblast surface antigen in the developing chick embryo. J Exp Med 142:41-49, 1975

22. Stenman S, Vaheri A: Distribution of a major connective tissue protein, fibronectin, in normal tissues. J Exp Med 147:1054-1063, 1978

23. Critchley DR, England MA, Wakely J, Hynes RO: Distribution of fibronectin in the ectoderm of gastrulating chick embryos. Nature 280:498-500, 1979

24. Donaldson DJ, Mahan JT: Fibrinogen and fibronectin as substrates for epidermal cell migration during wound closure. J Cell Sci 62: 117-127, 1983

25. Nishida T, Nakagawa S, Awata T, Ohashi Y, Watanabe K, Manabe R: Fibronectin promotes epithelial migration of cultured rabbit cornea in situ. J Cell Biol 97:1653-1657, 1983

26. Clark RA: Fibronectin in the skin. J Invest Dermatol 81:475-479, 1983

27. Gilchrest BA, Calhoun JK, Maciag T: Attachment and growth of human keratinocytes in a serum-free environment. J Cell Physiol 112:197-206, 1982

28. Stenn KS, Madri JA, Tinghitella T, Terranova VP: Multiple mechanisms of dissociated epidermal cell spreading. J Cell Biol 96: 63-67, 1983

29. Takashima A, Grinnell F: Human keratinocyte adhesion and phagocytosis promoted by fibronectin. J Invest Dermatol 83:352-358, 1984
30. Clark RA, Folkvord JM, Wertz RL: Fibronectin as well as other extracellular matrix proteins mediate human keratinocyte adherence. J Invest Dermatol 84:378-383, 1985

31. MacDonald JA, Kelley DG, Broekelmann TJ: Role of fibronectin in collagen deposition: Fab' to the gelatin-binding domain of fibronectin inhibits both fibronectin and collagen organization in fibroblast extracellular matrix. J Cell Biol 92:485-492, 1982

32. O'Keefe EJ, Payne RE Jr, Russell N, Woodley DT: Spreading and enhanced motility of human keratinocytes on fibronectin. J Invest Dermatol 85:125-130, 1985

33. Kleinman HK, Klebe RJ, Martin GR: Role of collagenous matrices in the adhesion and growth of cells. J Cell Biol 88:473-485, 1981

34. Takashima A, Grinnell F: Fibronectin-mediated keratinocyte migration and initiation of fibronectin receptor function in vivo. J Invest Dermatol 85:304-308, 1985

35. Takashima A, Billingham RE, Grinnell F: Activation of rabbit keratinocyte fibronectin receptor function in vivo during wound healing. J Invest Dermatol 86:585-590, 1986

36. Stenn KS, Milstone LM: Epidermal cell confluence and implications for a two-step mechanism of wound closure. J Invest Dermatol 83:445-447, 1984

37. Bohnert A, Hornung J, Mackenzie IC, Fusenig NE: Epithelial-mesenchymal interactions control basement membrane production and differentiation in cultured and transplanted mouse keratinocytes. Cell Tissue Res 244:413-429, 1986

38. Asselineau D, Bernard BA, Bailly C, Darmon M, Prunièras M: Human epidermis reconstructed by culture: is it "normal"? J Invest Dermatol 86:181-186, 1986

39. Briggaman RA, Dalldorf F, Wheeler CE Jr: Formation and origin of basal lamina and anchoring fibrils in adult human skin. J Cell Biol 51:384-395, 1971

40. Oh E, Pierschbacher M, Ruoslahti E: Deposition of plasma fibronectin in tissues. Proc Natl Acad Sci USA 78:3218-3221, 1981

41. Mosher DF, Schad PE, Kleinman HK: Cross-linking of fibronectin to collagen by blood coagulation factor XIIIa. J Clin Invest 64: $781-787,1979$

42. Kurkinen M, Vaheri A, Roberts PJ, Stenman S: Sequential appearance of fibronectin and collagen in experimental granulation tissue. Lab Invest 43:47-51, 1980

43. Viljanto J, Penttinen R, Rackallio J: Fibronectin in early phases of wound healing in children. Acta Chir Scand 147:7-13, 1981

44. Grimwood RE, Ferris CF, Nielsen LD, Huff JC, Clark RA: Basal cell carcinomas grown in nude mice produce and deposit fibronectin in the extracellular matrix. J Invest Dermatol 87:42-46, 1986 